\title{
Serial pulmonary function tests in patients with asbestosis
}

\author{
M. G. BRITTON, D. T. D. HUGHES, AND A. M. J. WEVER ${ }^{1}$
}

From the Pulmonary Research Unit, The Department of Chest Medicine, The London Hospital, London E1

Britton, M. G., Hughes, D. T. D., and Wever, A. M. J. (1977). Thorax, 32, 45-52. Serial pulmonary function tests in patients with asbestosis. Serial lung function tests were performed on 17 patients with asbestosis. A marked fall in the transfer factor often preceded any significant decline in the vital capacity. Changes in vital capacity and transfer factor did not appear to give any indication of the prognosis in these patients. Death was more commonly due to carcinoma of the lung than to the effects of the lung fibrosis.

The abnormalities of pulmonary function in patients with asbestosis have been well described (Williams and Hugh-Jones, 1960; Regan et al., 1971). In 1965 Bader et al. reported follow-up measurements on 13 asbestos workers using vital capacity, maximum breathing capacity, and blood gas measurements. They concluded that vital capacity was the most sensitive index of progression of the disease and correlated well with radiological changes and progression of dyspnoea in half the cases. However, reports of serial studies in patients with asbestosis are rare and we have been unable to find a study with serial measurements of transfer factor.

A retrospective study of 120 patients who had lung function tests at The London Hospital for possible asbestosis between 1960 and 1975 showed that, by 1975,50 had proven asbestosis and nine had mesothelioma (Britton and Hughes, 1976). The 50 patients have produced a group of 17 in whom serial lung function tests were carried out over a 4- to 12-year period. The data from these patients have been studied to determine whether pulmonary function tests, especially the vital capacity and transfer factor, might be helpful in predicting the prognosis in cases of asbestosis.

\section{Patients and methods}

The 17 patients were in- or out-patients at The London Hospital and were referred to the Lung Function Laboratory for an assessment of pul-

'Present address: University Hospital, Nijmegen, The Netherlands monary function. Each patient performed tests of peak flow rate, forced expiratory volume in one second $\left(\mathrm{FEV}_{1}\right)$, forced vital capacity $(\mathrm{FVC})$, and $\mathrm{PCO}_{2}$. The transfer factor was estimated twice by the single breath carbon monoxide method using a Resparameter and the mean result was recorded. The methods used in the laboratory for these tests have already been described (Hughes and Empey, 1972), and the predicted values were those of Cotes (1968).

All patients fulfilled the mandatory criteria for the diagnosis of asbestosis (Parkes, 1973) by the time of their most recent assessment. These are:

1 definite asbestos exposure;

2 bilateral basal crepitations;

3 radiological changes of diffuse interstitial fibrosis in the lower halves of the lung fields;

4 impairment of lung function.

Clubbing, pleural plaques, dyspnoea on effort, and the demonstration of asbestos bodies in the sputum provide corroborative evidence. In a few cases crepitations may be absent in the presence of early radiographic evidence of asbestosis.

The patients had tests on more than one occasion, and all of them had no further asbestos exposure after their first tests. Hence the changes shown in the serial tests represent the natural history of asbestosis rather than any changes from further exposure.

\section{Results}

The results for $\mathrm{FEV}_{1}$, peak flow, and $\mathrm{PCO}_{2}$ are not reported since the most significant changes were in FVC and transfer factor. In fact in no case 
was the $\mathrm{PCO}_{2}$ elevated while the $\mathrm{FEV}_{1} / \mathrm{FVC}$ ratio was less than $70 \%$ in only two cases. Some relevant data concerning the 17 patients, including their smoking habits are shown for convenience in Table 1. All the patients had abnormal radiographs by the end of the study, and all except patients 8,10 , and 15 are known to have received a pneumoconiosis board pension.

\section{INITIAL RESULTS}

The results of the initial tests of the 17 patients expressed as a percentage of predicted values are shown in Table 2.

Assuming a normal value to be greater than $75 \%$ of predicted, the patients may be divided into the following groups:
1 three patients $(3,5$, and 9) with normal values for both vital capacity and transfer factor;

2 eight patients $(1,4,6,7,8,10,11$, and 1 का with a normal vital capacity but an impaired transfer factor;

3 one patient (12) with an abnormal vitâl capacity with a normal transfer factor;

4 five patients $(2,13,14,16$, and 17) with im. paired values of both.

SERIAL STUDIES

All the patients had lung function tests performed on a variable number of occasions (Table 1). The serial changes in each individual's vital capacity and transfer factor in absolute values are plottee either against the number of years before deatit

Table 1 Characteristics of the patients with serial lung function tests

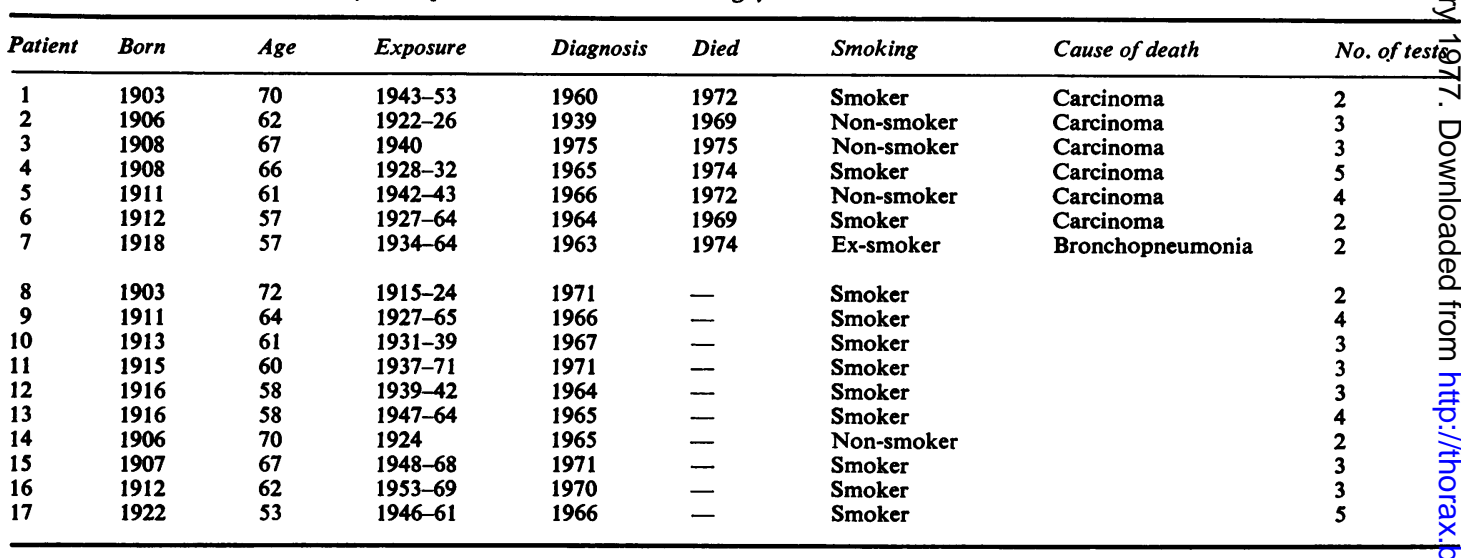

Table 2 Initial results of all patients with relationships to first exposure

\begin{tabular}{llll}
\hline Patient & $\begin{array}{l}\text { Time from first } \\
\text { exposure to } \\
\text { initial test } \\
\text { (years) }\end{array}$ & $\begin{array}{l}\text { Vital capacity } \\
\text { as } \% \text { of } \\
\text { predicted }\end{array}$ & $\begin{array}{l}\text { Transfer factor } \\
\text { as \% of predicted }\end{array}$ \\
\hline 1 & 17 & 85 & \\
2 & 40 & 50 & 61 \\
3 & 32 & 99 & 65 \\
4 & 38 & 91 & 81 \\
5 & 24 & 83 & 48 \\
6 & 38 & 96 & 100 \\
7 & 30 & 75 & 60 \\
8 & 50 & 76 & 68 \\
9 & 39 & 94 & 34 \\
10 & 36 & 92 & 96 \\
11 & 34 & 84 & 63 \\
12 & 25 & 45 & 65 \\
13 & 21 & 52 & 88 \\
14 & 42 & 64 & 67 \\
15 & 20 & 84 & 58 \\
16 & 17 & 54 & 43 \\
17 & 20 & 49 & 50 \\
\hline
\end{tabular}

in the seven patients who had died (Figs. 1 and $\$$ or against the date in years for those still living (Figs. 3 and 4).

In order to appreciate the interrelationsh between vital capacity and transfer factor various stages of the disease the serial tests of three patients, each a representative example of one of the three main groups, are illustrated:
Group 1
Patient 9
Fig. 5
Group 2
Patient 10
Fig. 6
Group 4
Patient 17
Fig. 7

The percentages in parentheses on these grap represent the percentage of predicted values at the time of the initial test.

Some comparisons have also been made bet tween those patients who have died (1-7) an those patients who are still living (8-17). The changes in absolute values and percentage of pre dicted values for both vital capacity and transfer 
factor are expressed as the average yearly fall. These results together with the average values of the last tests, which were all within one year either of death or the end of the study, are all shown in Table 3.

The serial results of one patient who died (5) are shown in Figure 8.

In all three patients in group 1 (with both vital capacity and transfer factor initially within the normal range) a marked fall in the transfer factor preceded any significant change in the vital capacity (Figs. 5 and 8). This is further supported by the eight patients of group 2 whose initial tests already showed an impaired transfer factor but a normal vital capacity.

After this initial fall in the transfer factor there appeared to be a steady decline in both vital capacity and transfer factor of equal proportions,

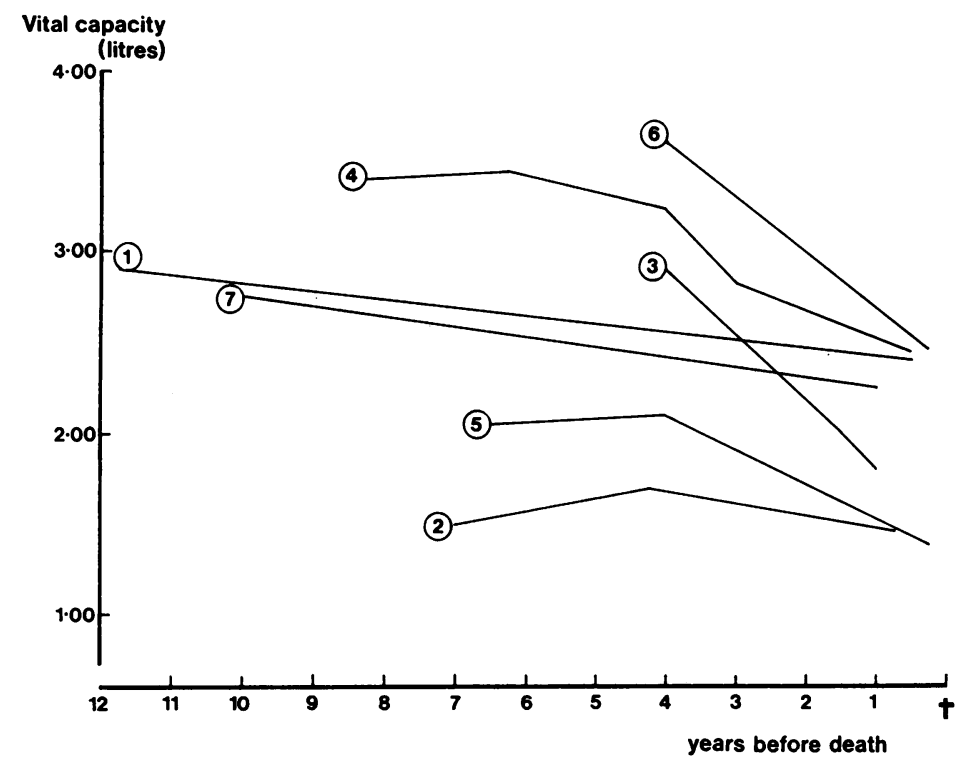

Transfer factor

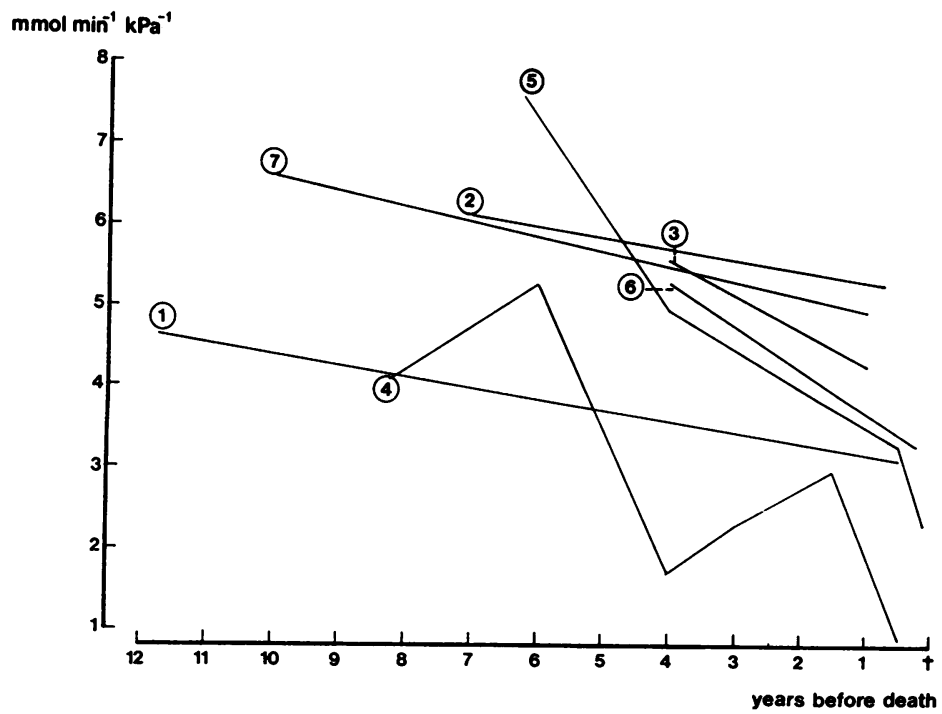

Fig. 1 Serial studies of vital capacity in patients 1-7.

Fig. 2 Serial studies of transfer factor in patients 1-7. See Fig. 6 for conversion to traditional units. 


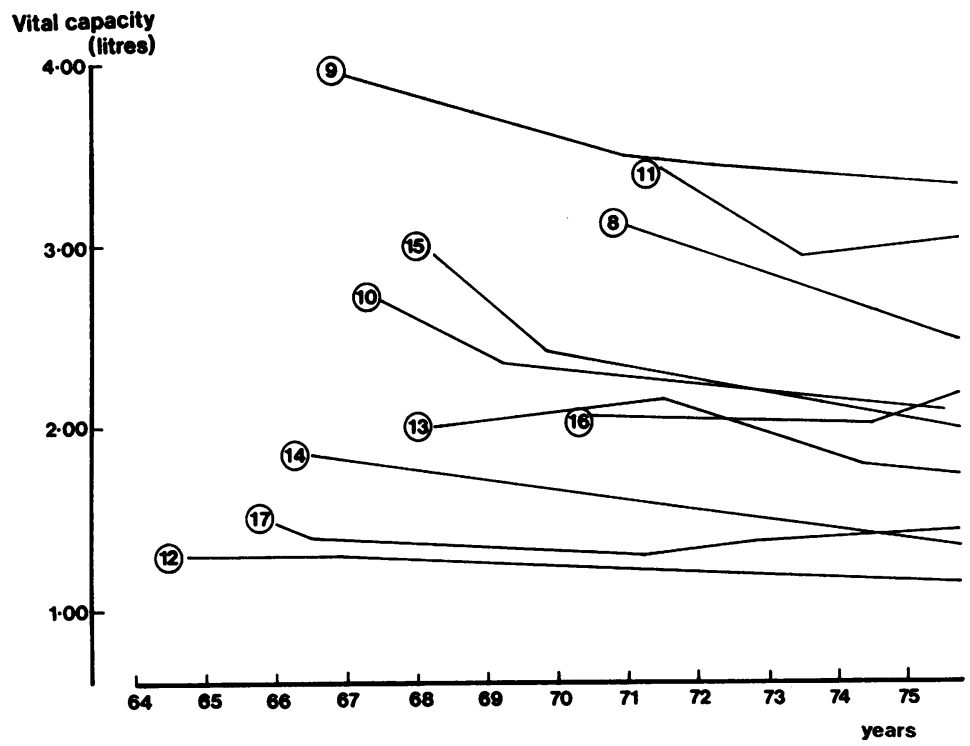

Fig. 3 Serial studies of vital capacity in living patients 8-17.

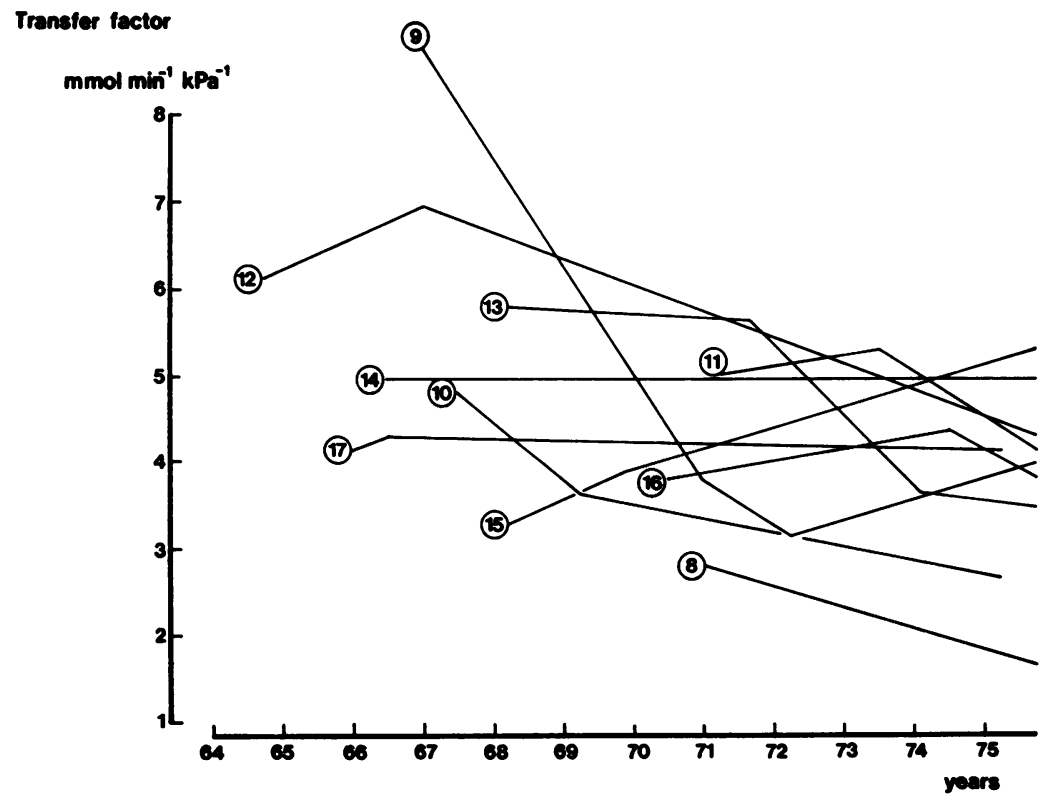

Fig. 4 Serial studies of transfer factor in living patients 8-17. 
Transfer factor
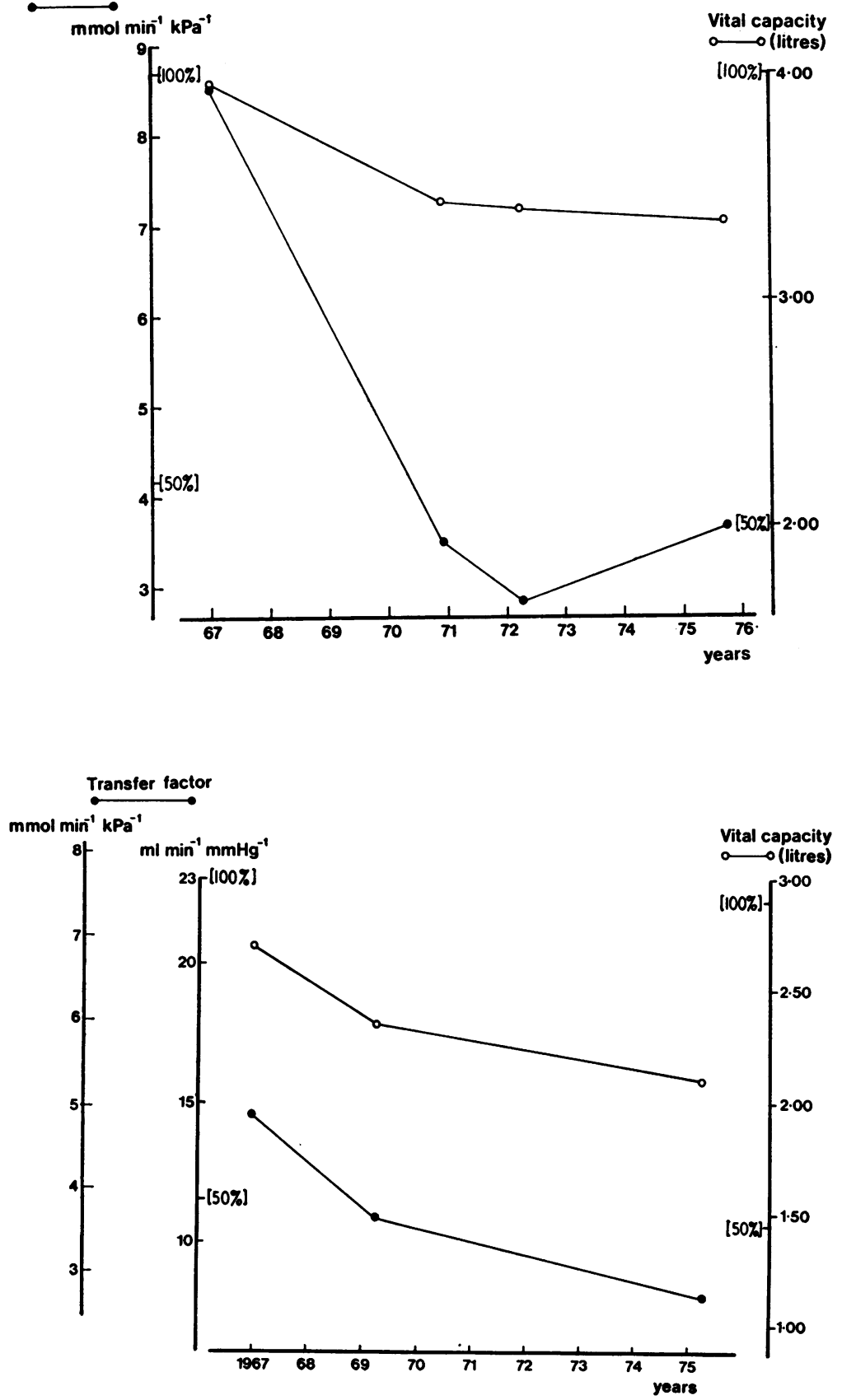

Fig. 5 Serial changes in transfer factor and vital capacity of patient 9 (the percentages in parentheses represent the percentage of predicted values at the time of the first test).

Fig. 6 Serial changes in transfer factor and vital capacity of patient 10. 


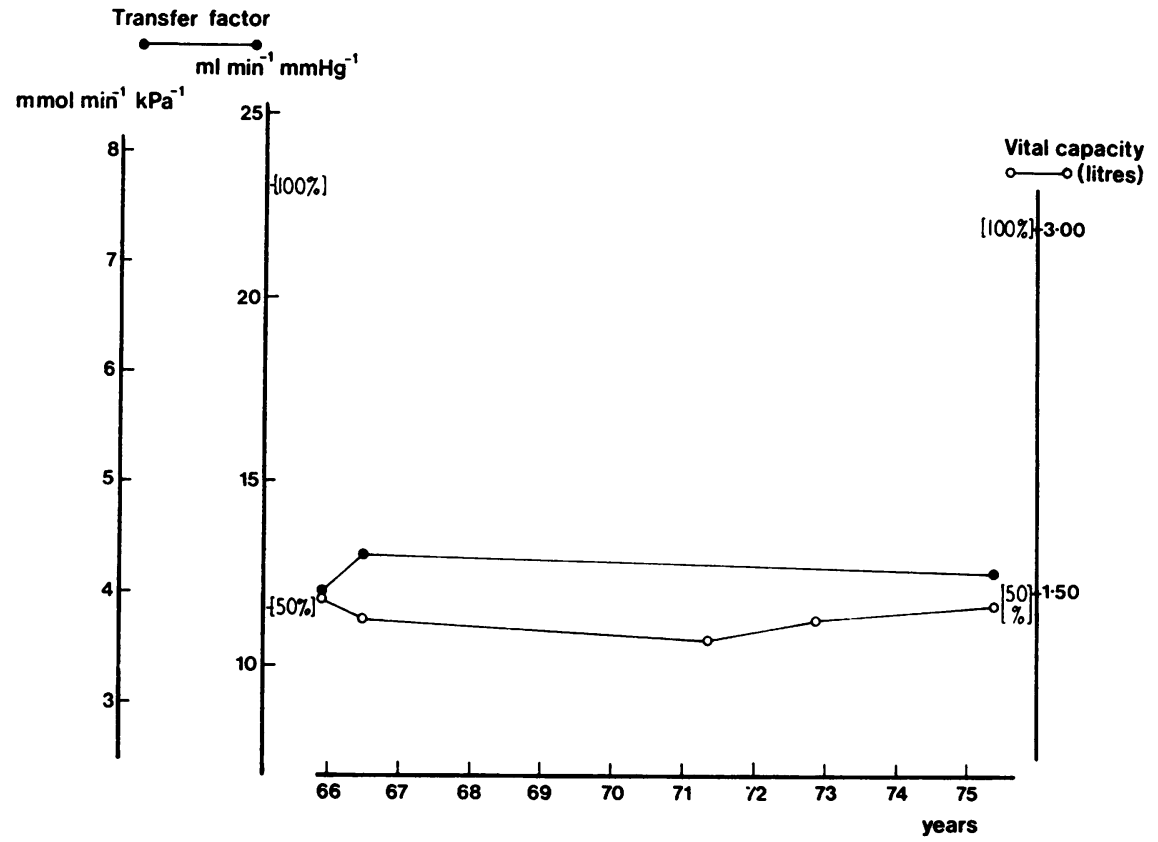

Fig. 7 Serial changes in transfer factor and $\mathrm{O}$
vital capacity of patient 17.

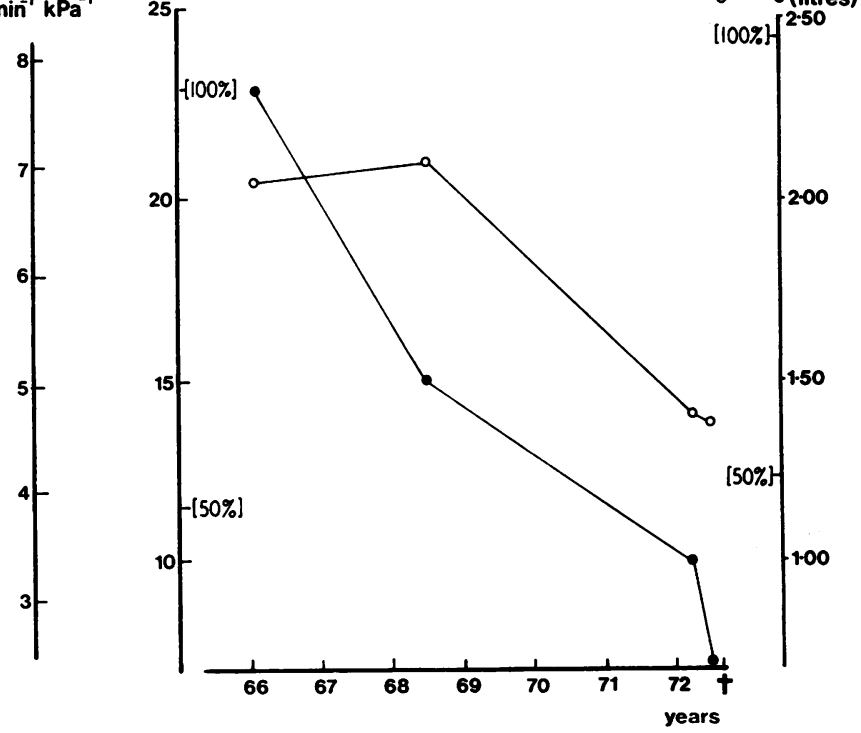

Fig. 8 Serial changes in transfer factor and vital capacity of patient 5 . 
Table 3 Some comparisons between the living and dead patients

\begin{tabular}{|c|c|c|c|c|c|c|c|c|c|c|}
\hline \multirow[t]{3}{*}{ Patient } & \multirow{3}{*}{$\begin{array}{l}\text { Average } \\
\text { age on } \\
\text { l Dec.' } 75 \\
\text { or at } \\
\text { death }\end{array}$} & \multirow{3}{*}{$\begin{array}{l}\text { Average no. } \\
\text { of years } \\
\text { since first } \\
\text { exposure }\end{array}$} & \multicolumn{4}{|c|}{ Average yearly fall in } & \multirow{2}{*}{\multicolumn{4}{|c|}{$\begin{array}{l}\text { Average values within a year of death or end } \\
\text { of study of }\end{array}$}} \\
\hline & & & Transfer & $\%$ of & Vital & $\%$ of & & & & \\
\hline & & & $\begin{array}{l}\text { factor } \\
(\text { mmol } \\
\mathrm{min}^{-1} \\
\left.k \mathrm{~Pa}^{-1}\right)\end{array}$ & $\begin{array}{l}\text { predicted } \\
\text { TF }\end{array}$ & $\begin{array}{l}\text { capacity } \\
(m l)\end{array}$ & $\begin{array}{l}\text { predicted } \\
\text { VC }\end{array}$ & $\begin{array}{l}\text { Transfer } \\
\text { factor } \\
(\text { mmol } \\
\text { min }^{-1} \\
\left.k P a^{-1}\right)\end{array}$ & $\begin{array}{l}\% \text { of } \\
\text { predicted } \\
T F\end{array}$ & $\begin{array}{l}\text { Vital } \\
\text { capacity } \\
(m l)\end{array}$ & $\begin{array}{l}\% \text { of } \\
\text { predicted } \\
V C\end{array}$ \\
\hline $\begin{array}{l}1-7 \text { (dead) } \\
8-17 \text { (alive) }\end{array}$ & $\begin{array}{l}63 \\
62\end{array}$ & $\begin{array}{l}39 \\
38 \cdot 3\end{array}$ & $\begin{array}{l}0.41 \\
0.15\end{array}$ & $\begin{array}{l}4 \cdot 25 \\
1 \cdot 78\end{array}$ & $\begin{array}{r}140 \\
58\end{array}$ & $\begin{array}{l}3 \cdot 79 \\
0 \cdot 65\end{array}$ & $\begin{array}{l}3 \cdot 55 \\
3 \cdot 92\end{array}$ & $\begin{array}{l}44 \cdot 3 \\
51 \cdot 2\end{array}$ & $\begin{array}{l}2,050 \\
2,100\end{array}$ & $\begin{array}{l}62 \cdot 7 \\
64 \cdot 2\end{array}$ \\
\hline
\end{tabular}

Conversion: SI to traditional units-Transfer factor: $1 \mathrm{mmol} \mathrm{min}{ }^{-1} \mathrm{kPa}^{-1} \approx 2.9 \mathrm{ml} \mathrm{min}^{-1} \mathrm{mmHg}^{-1}$.

probably lasting over an 8-12 year period. Patient 10 (Fig. 6) is shown as an example of these changes which were seen in the patients of group 2. The vital capacities rarely fell below $50 \%$ of predicted, and $40 \%$ of predicted for the transfer factor.

Finally, the patients in group 4 showed constant but impaired values throughout their period of study, varying from six to nine years, the only exception being a gentle decline in the transfer factor of patient 13. Figure 7 shows the results of patient 17 with a vital capacity of 1.45 litres and a transfer factor of $4 \mathrm{mmol} \mathrm{min}{ }^{-1} \mathrm{kPa}^{-1}(11.9 \mathrm{ml}$ $\min ^{-1} \mathrm{mmHg}^{-1}$ ), both measurements remaining constant over a nine-year period, as an example of this group.

The chest radiograph of patient 12 , taken at the time of presentation, showed extensive pleural fibrosis in the left hemithorax with calcified plaques over both diaphragms. This possibly explains why the vital capacity was impaired before there was any change in the transfer factor.

\section{Discussion}

Although the changes seen varied with the different groups, it appeared that after a variable interval of time following exposure to asbestos there is an initial marked fall in the transfer factor which precedes any significant decline in the vital capacity. This was followed by a steady decline in the vital capacity of most of the patients, greater than one would expect due to aging alone, thus supporting the findings of Bader et al. (1965).

Perhaps the changes seen in the three main groups of patients may represent the disease process at different stages of its development, and it might be postulated that in the patients of group 4 the disease has burnt itself out. However, there was no correlation between the functional changes seen initially and the date and duration of exposure.

Death may occur at any time along this progression and, of the seven deaths in this study, six were from carcinoma, and three of these were non-smokers (2, 3, and 5). The emergence of a carcinoma of the lung in these patients did not appear to make any significant differences to the lung function tests, although in the terminal stages of the illness there may be a more rapid decline in the vital capacity and/or transfer factor (Fig. 8).

In our experience with this small number of patients, serial lung function tests, although useful in diagnosis, appear to be of little help in assessing the prognosis of individual cases of asbestosis. There is a need for further longitudinal studies to include more frequent measurements and correlation with radiological changes in the lung and pleura.

We are indebted to the Wellcome Foundation for financial support.

\section{References}

Bader, M. E., Bader, R. A., Tierstein, A. S., and Selikoff, I. J. (1965). Pulmonary function in asbestosis: serial tests in a long-term prospective study. Annals of the New York Academy of Science, 132, 391-405.

Britton, M. G. and Hughes, D. T. D. (1976). A survey of patients diagnosed as having asbestosis. Medicine, Science and the Law, 16, 279-284.

Cotes, J. E. (1968). Lung Function. Assessment and Application in Medicine, 2nd edition, pp. 364-365. Blackwell Scientific Publications, Oxford.

Hughes, D. T. D. and Empey, D. W. (1972). Ten years' experience in running a pulmonary function laboratory. British Medical Journal, 4, 470-473.

Parkes, W. R. (1973). Asbestos-related disorders. British Journal of Diseases of the Chest, 67, 261300.

Regan, G. M., Tagg, B., Walford, J., and Thomson, 
M. L. (1971). The relative importance of clinical, radiological and pulmonary function variables in evaluating asbestosis and chronic obstructive airway disease in asbestos workers. Clinical Science, 41, 569-582.

Williams, R. and Hughes-Jones, P. (1960). The significance of lung function changes in asbestosis. Thorax, 15, 109-119.

Requests for reprints to: Dr. D. T. D. Hughes, Theo London Hospital, London E1. 